\title{
PERCEPÇÃO AMBIENTAL DOS MORADORES DO BEIJA-FLOR QUANTO À REMOÇÃO DAS MATAS CILIARES, MUNICÍPIO DE MAZAGÃO
}

Kerlency Maria Farias Santos-

kerlency98@gmail.com

UEAP- Universidade do Estado do Amapá

Olavo Bilac Quaresma de Oliveira Filhoolavo.filho@ueap.edu.br

UEAP- Universidade do Estado do Amapá 


\section{RESUMO}

A mata ciliar é um tipo de cobertura vegetal nativa que cobre margem de rios, igarapés, lagos, sendo elemento de extrema importância, pois mantêm a qualidade da água, impedem que haja erosão do solo, entre outros, se encaixando segundo a lei $n^{\circ}$ 12.651/2012 nas áreas de proteção permanente (APP). Entretanto, ocupações irregulares colocam em risco este equilíbrio ecológico quando há retirada dessas matas ciliares, o que compromete a qualidade da água, por conta da erosão do solo, despejo de resíduos diretamente no rio, colocando em risco a biodiversidade da fauna e flora da região. Este projeto buscou analisar a percepção ambiental dos moradores na área do furo do rio beijaflor no município de Mazagão-AP, esta percepção pode ser usada como indicador de impactos ambientais da mudança do equilíbrio natural com o passar dos anos e propor medidas que poderiam minimizar de forma efetiva tais impactos envolvendo também a questão social e a realidade local dos moradores.

\section{INTRODUÇÃO}

No Estado do Amapá, vem ocorrendo o crescimento populacional e consequentemente o crescimento das cidades onde se concentra a maior quantidade de emissão de efluentes. Entretanto, também há degradação do meio ambiente em localidades longe do aglomerado urbano, como no caso das residências construídas às margens do furo do rio beija-flor no município de Mazagão, cidade de Mazagão Novo, o qual é o objeto de estudo do presente projeto, locais em que deveria haver controle ambiental do uso e ocupação do solo do município como um todo, por parte do poder público municipal, isto ocorre pela ausência de um plano diretor, segundo Braga (2001) é o principal instrumento de gestão ambiental urbana, sobretudo pelo fato de não ter uma política ambiental sistematizada em nível municipal. Além do aumento desordenado da habitação na região, também há o loteamento dos terrenos as margens do referido rio para venda, com o intuito de construção de casas nesta área ocorrendo a retirada das matas ciliares.

Entende-se por vegetação ciliar ou ripária, aquela que margeia as nascentes e os cursos de água (MARTINS, 2007). As matas ciliares são fornecedoras de diversos benefícios ao meio ambiente dentre eles destacam-se: o controle à erosão nas margens dos rios e córregos; a redução dos efeitos de enchentes; manutenção da quantidade e qualidade das águas; filtragem de resíduos de produtos químicos como agrotóxicos e fertilizantes (MARTINS, 2007)."As matas ciliares possuem a função de proteger os rios, riachos, córregos e o entorno dos lagos e lagoas contra as intempéries provocadas pela própria natureza, bem como pela ação humana" (Vieira, 2013, p.2). Apesar dessas áreas serem muitas vezes habitadas, elas são protegidas pelo novo Código Florestal, conforme a lei $\mathrm{n}^{\circ}$ 12.651, de 25 de maio de 2012 em que se encaixam em área de proteção permanente (APP).

A percepção dos riscos ambientais constitui um dos temas que vem sendo muito abordado no campo da percepção ambiental, onde se busca enfatizar as tomadas de decisão, ou seja, as respostas humanas aos riscos dos níveis individual, comunitário e nacional (BURTON, 1978). Faggionato (2009) define percepção ambiental como sendo uma tomada de consciência do ambiente pelo homem, ou seja, o ato de perceber o 
ambiente que se está inserido, aprendendo a proteger e a cuidar do mesmo. Cada indivíduo percebe, reage e responde diferentemente às ações sobre o ambiente em que vive. A partir dessa percepção, o indivíduo interage com o mundo, influencia seus pares, intervém no ambiente, caminha na direção do processo de conhecimento e do exercício da cidadania ambiental (FERNANDES et al., 2009).

Portanto, o presente projeto visou desenvolver um estudo socioambiental, através da percepção ambiental referente às matas ciliares dos moradores do Rio BeijaFlor e da comunidade de Mazagão Novo-AP; analisar a percepção ambiental referente à preservação das matas ciliares considerando as respostas destes moradores e confeccionar produtos através de gráficos, dos diagnósticos da área estudada que facilite a utilização destes pela gestão pública, comunidade científica e sociedade.

\section{METODOLOGIA}

Como método de avaliação da percepção ambiental dos moradores do município de Mazagão-AP que vivem às margens do rio beija-flor, foi aplicado um questionário com 14 perguntas. Foram selecionadas perguntas fechadas. O questionário foi realizado com pessoas maiores de 14 anos, moradores mais antigos (acima de 15 anos de residência no local) e recentes (até 5 anos de residência no local) para que houvesse ampla visão dos aspectos e mudanças ambientais.

A quantidade de questionários aplicados foi baseada em métodos estatísticos de quantidade mínima de confiabilidade, utilizando o cálculo para identificação das unidades de amostra pela fórmula de TAGLIACARNE (1978), o número de entrevistados deve ser representativo para a população. Segundo IBGE (2016), o município de Mazagão possui uma população de aproximadamente 19.981 habitantes. Segundo os cálculos, o número mínimo de entrevistados foi de 70 pessoas (quantidade adotada no trabalho), o que representa $0,34 \%$ da população. A aplicação dos questionários foi realizada em 5 dias não sequentes, dias 11, 12 e 21 de janeiro, 5 e 8 de fevereiro, todos em 2017. A área em que os questionários foram aplicados pode ser observada na Figura 1, feito em 13 pontos ao longo do rio Beija-Flor. 


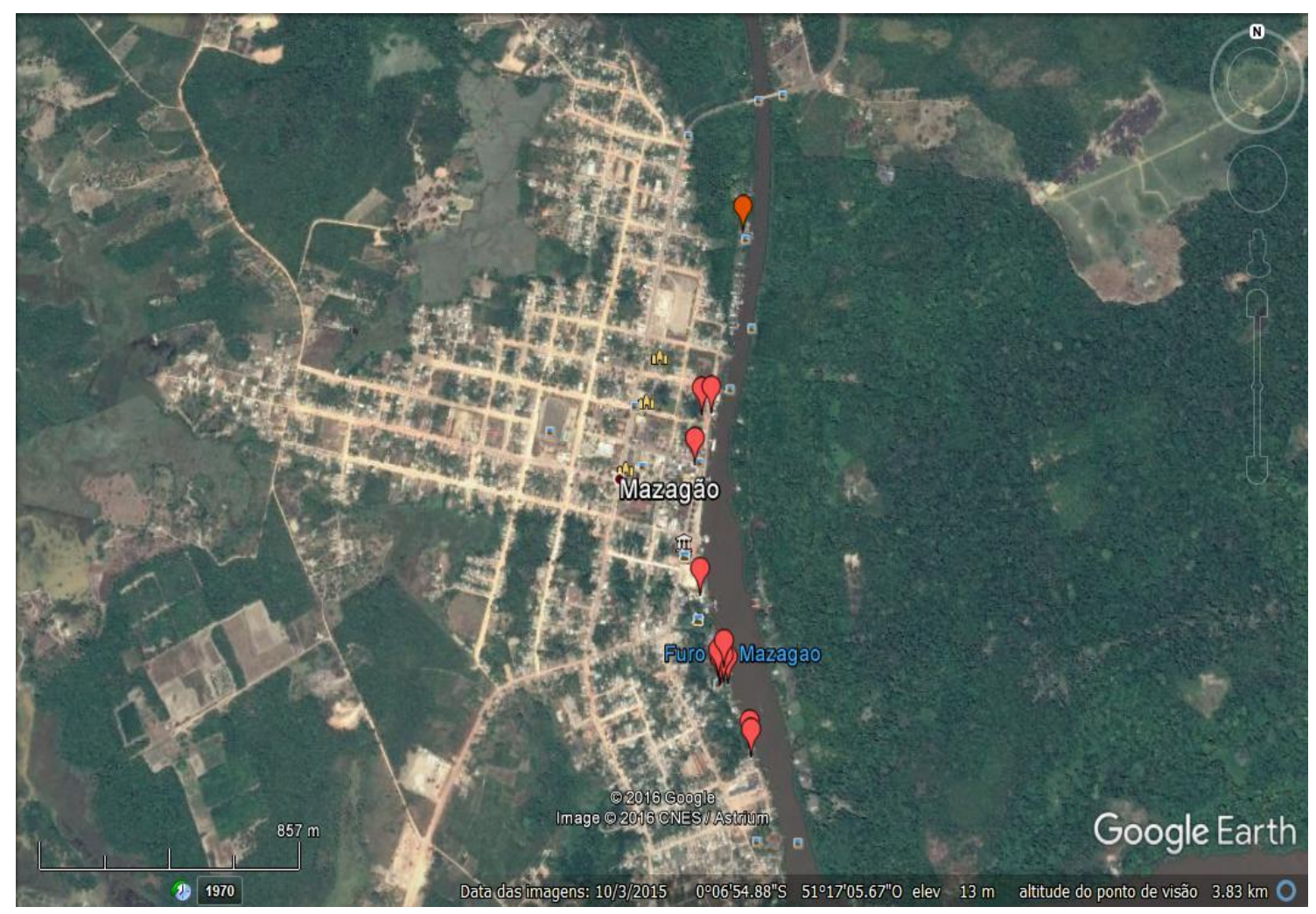

FIGURA 1 - Pontos de aplicação do questionário às margens do rio Beija-Flor, em Mazagão Novo-AP.

Fonte: Adaptado de Google (@2016).

\section{RESULTADOS E DISCUSSÃO}

Grande parte das pessoas consegue perceber que, de alguma forma, causa algum dano ao meio ambiente em que habita. Por isso, concorda-se com Tuan (1980, p. 2) que: “[...] numa visão mais ampla, sabemos que as atitudes e crenças não podem ser excluídas nem mesmo da abordagem prática, pois é prático reconhecer as paixões humanas em qualquer cálculo ambiental" (Ibid., p. 2).

$\mathrm{Na}$ primeira questão colocada, em que buscou-se compreender o quanto as pessoas tratam o tema meio ambiente em seu dia-a-dia, $60 \%$ dos entrevistados afirmaram que o tema meio ambiente é tratado em seu cotidiano e que isso se dá principalmente por morarem às margens do rio e terem contato direto com a natureza. Isto pode ser observado no gráfico da FIGURA 2 


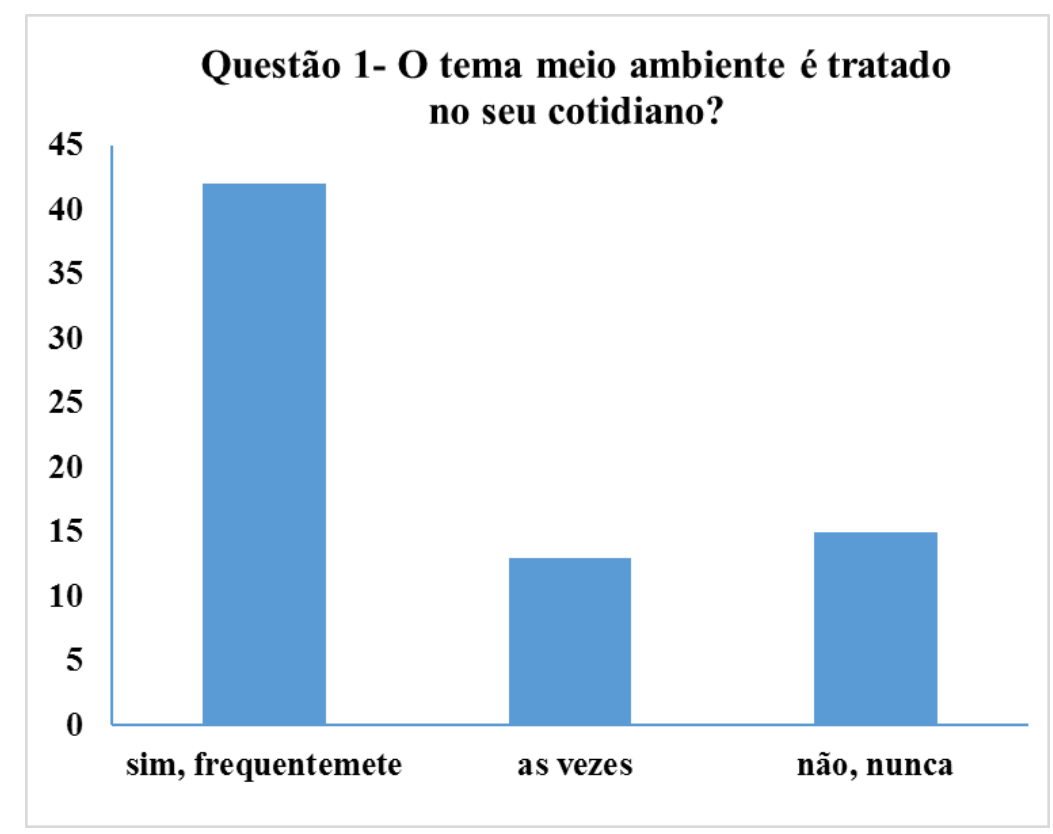

FIGURA 2 - Questão 1 (O tema meio ambiente é tratado no seu cotidiano?).

Em casos isolados foi discutido rapidamente em séries iniciais do ensino fundamental. Segundo Dias (1992) "sabe-se que a maioria dos problemas ambientais tem suas raízes em fatores socioeconômicos, políticos e culturais, e que não podem ser previstos ou resolvidos por meios puramente tecnológicos", com isto destaca-se a grande importância da educação ambiental nas escolas com o objetivo de colaborar na conscientização e conhecimento a respeito do meio ambiente tornando os alunos cidadãos comprometidos com a conservação de seu meio.

Apesar da carência de estudos ambientais na educação básica, o senso crítico de cada um alerta para a consciência de que as atividades cotidianas alteram o meio ambiente. Aproximadamente $75 \%$ dos entrevistados percebem que causam danos ao local em que habitam segundo o gráfico da FIGURA 3.

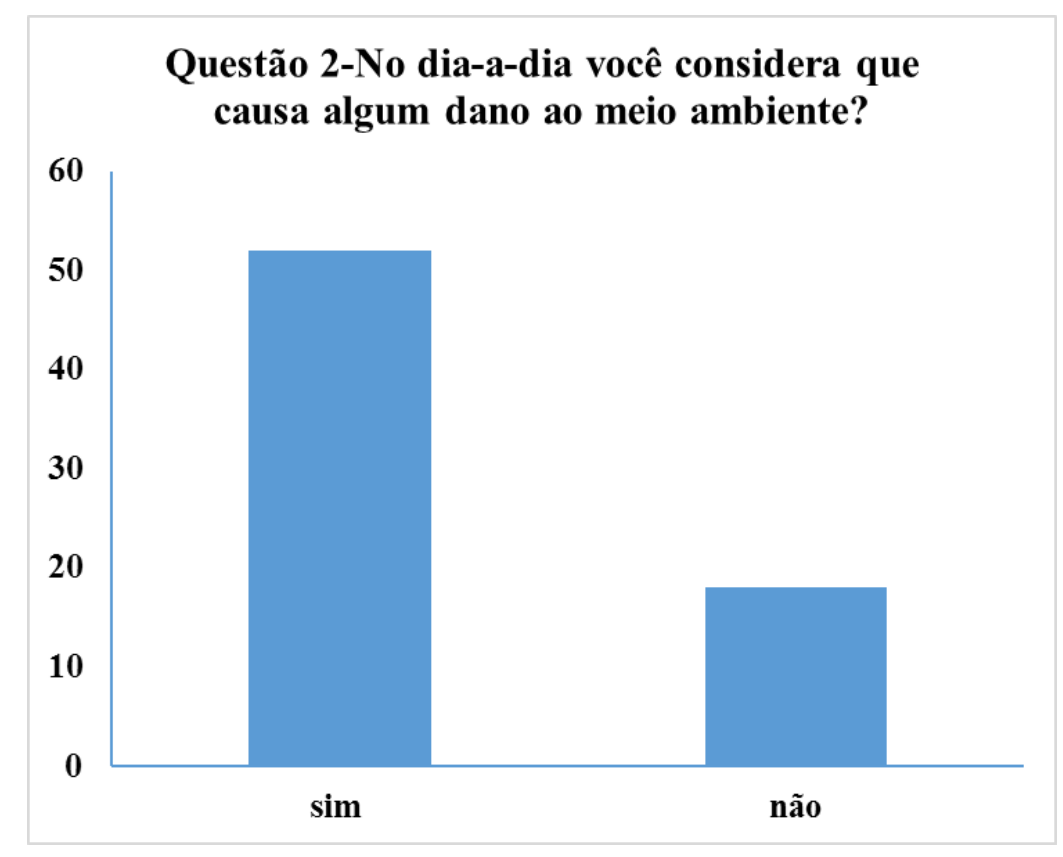


FIGURA 3- Questão 2 (No dia-a-dia você considera que causa algum dano ao meio ambiente?)

Apesar da percepção que o espaço está sendo alterado ao longo do tempo, o gráfico da FIGURA 4 mostra que 57\% dos entrevistados não tem conhecimento algum sobre áreas de preservação permanente. O que acaba enfatizando a carência na área de educação ambiental.

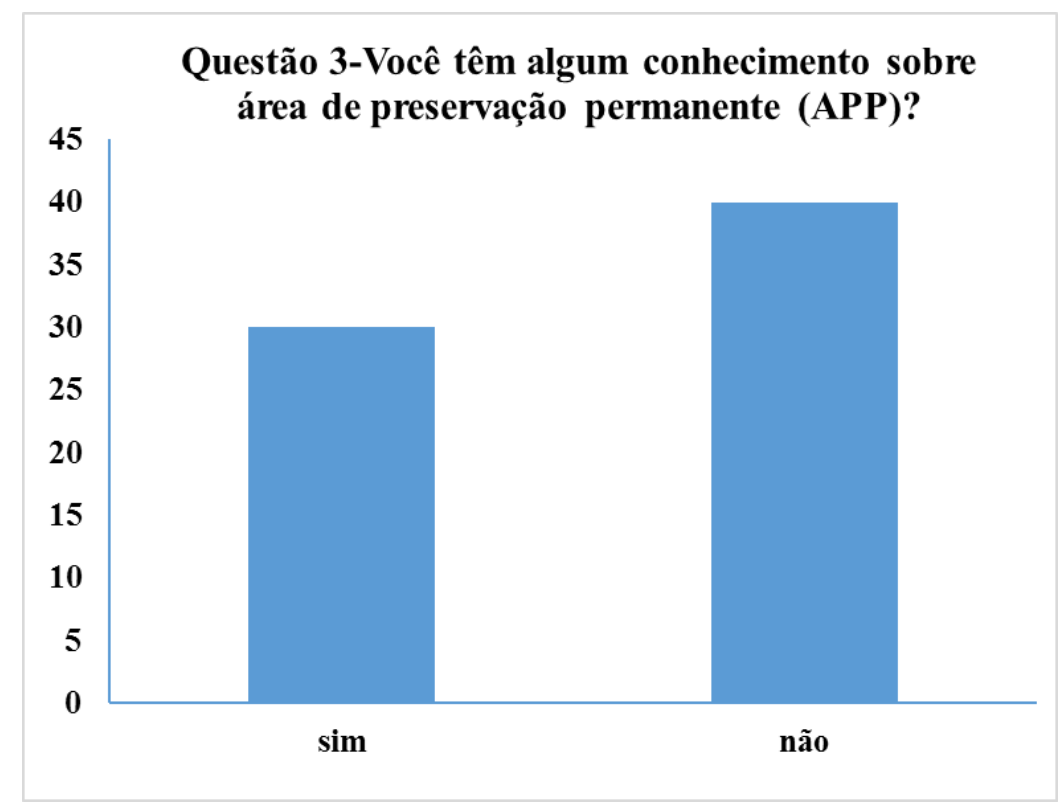

FIGURA 4- Questão 3 (Você têm algum conhecimento sobre área de preservação permanente (APP)?)

Apesar das diferentes faixas etárias e de tempo de residência na área, 85,7\% dos entrevistados responderam que se sentem incomodados com algum tipo de aspecto relacionados ao meio ambiente. Estes incômodos são, em sua maioria, causados por ações do homem e sua relação com o meio ambiente.

O maior problema percebido pelos moradores foi quanto à poluição do rio. Cerca de $74,2 \%$ das respostas apontam a poluição do rio como principal incômodo conforme FIGURA 5, e relatos dos moradores indicam o despejo de resíduos sólidos como maior problema enfrentado.

A cidade não possui tratamento de esgoto e todos os resíduos são despejados no rio. Apesar de se tratar de uma cidade pequena, a pesquisa serve de alerta para o futuro agravamento de problemas ambientais. Segundo Gloagen et al (2007) a falta de políticas públicas é um agravante por culminar na falta de planejamento do uso dos recursos hídricos, do solo e das matas ciliares.

O processo de degradação da mata ciliar resulta na perda qualiquantitativa da água, biodiversidade, controle da erosão, redução dos efeitos de enchentes, filtragem de resíduos químicos e sólidos. E ainda adverte Fellenberg (1980), a preservação ambiental das margens dos rios deverá nos preocupar bastante no futuro, pois em todas as regiões em que as reservas de água subterrâneas se esgotarem a solução para garantir o abastecimento de água potável será o aproveitamento da água de represa, lagos e rios. Se estas águas superficiais estiverem excessivamente contaminadas, o tratamento da água será muito dispendioso. 


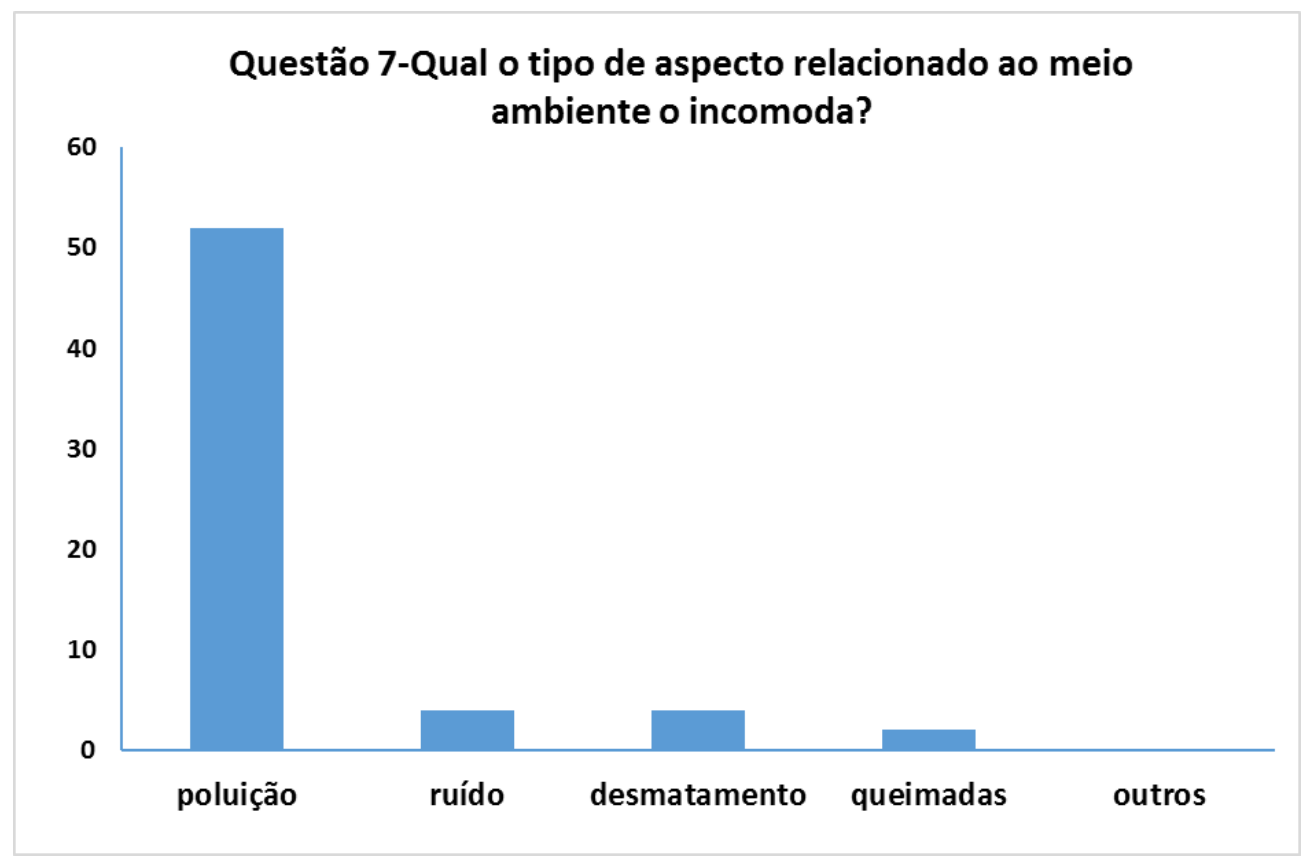

FIGURA 5- Questão 7 (Qual tipo de aspecto relacionado ao meio ambiente o incomoda?)

As dificuldades encontradas pela população quanto à poluição e o que poderia ser feito para amenizar a situação obteve respostas relativamente equilibradas quando questionados se atitudes foram tomadas com relação ao incômodo sofrido, mas a maioria das respostas apresentaram posicionamento positivo a atitudes para mudar a realidade (FIGURA 6). Os moradores fazem aquilo que está ao alcance, como recolher o lixo que se acumula nas margens do rio, mas em poucos casos foi relatado medidas quanto ao despejo de resíduos que poluem a água em grandes proporções, como o destino dado ao óleo de cozinha utilizado.

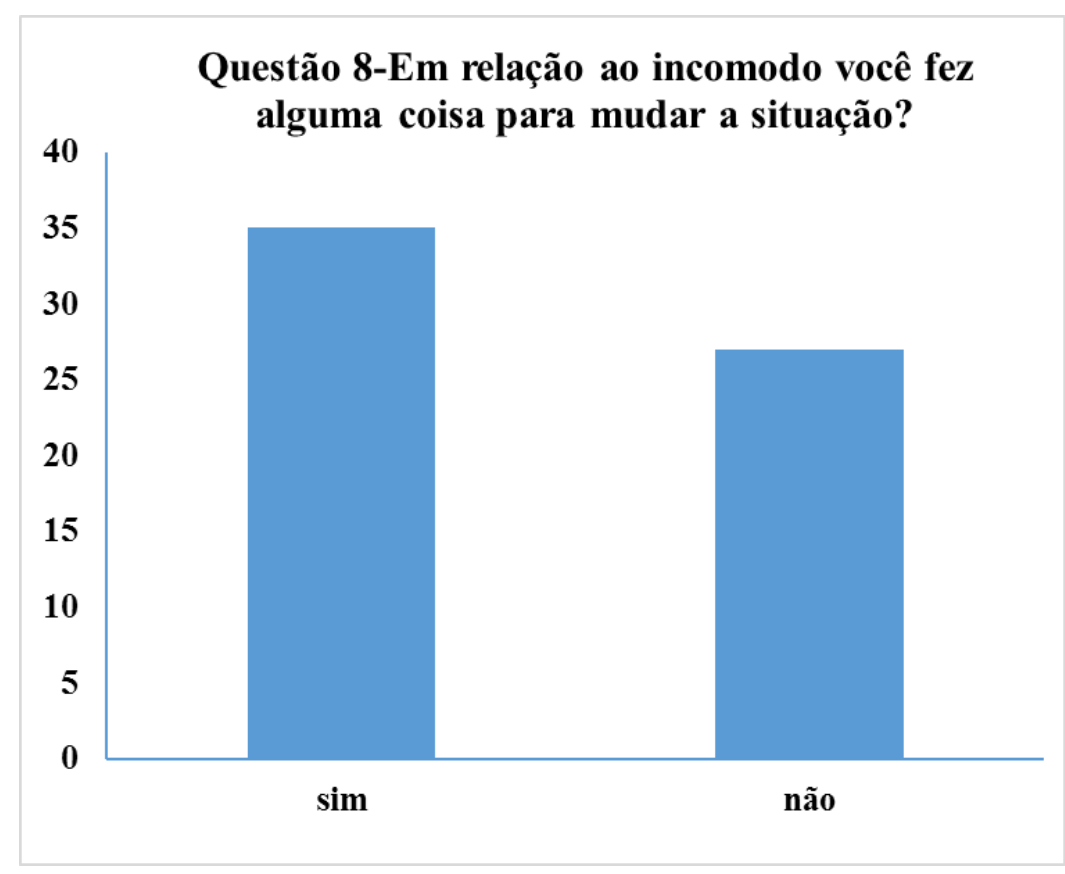

FIGURA 6- Questão 8(Em relação ao incomodo você fez alguma coisa para mudar a situação?) 
Quando questionados sobre o conhecimento de órgãos de proteção ao meio ambiente 52\% dos entrevistados não tinham conhecimento sobre a existência ou atuação destes órgãos (FIGURA 7). O que aponta falha na atuação e fiscalização destes sobre áreas que margeiam rios e que deveriam ser preservadas, e quanto ao controle da construção de residências nestas áreas.

É de fundamental importância que órgãos ambientais atuem na fiscalização dessas áreas pois a natureza coletiva do meio ambiente impõe ao poder público o dever de orientar o uso dos recursos naturais de forma que seja mantida a capacidade produtiva dos diferentes sistemas e compartimentos ambientais (MONTAÑO e SOUZA, 2008),

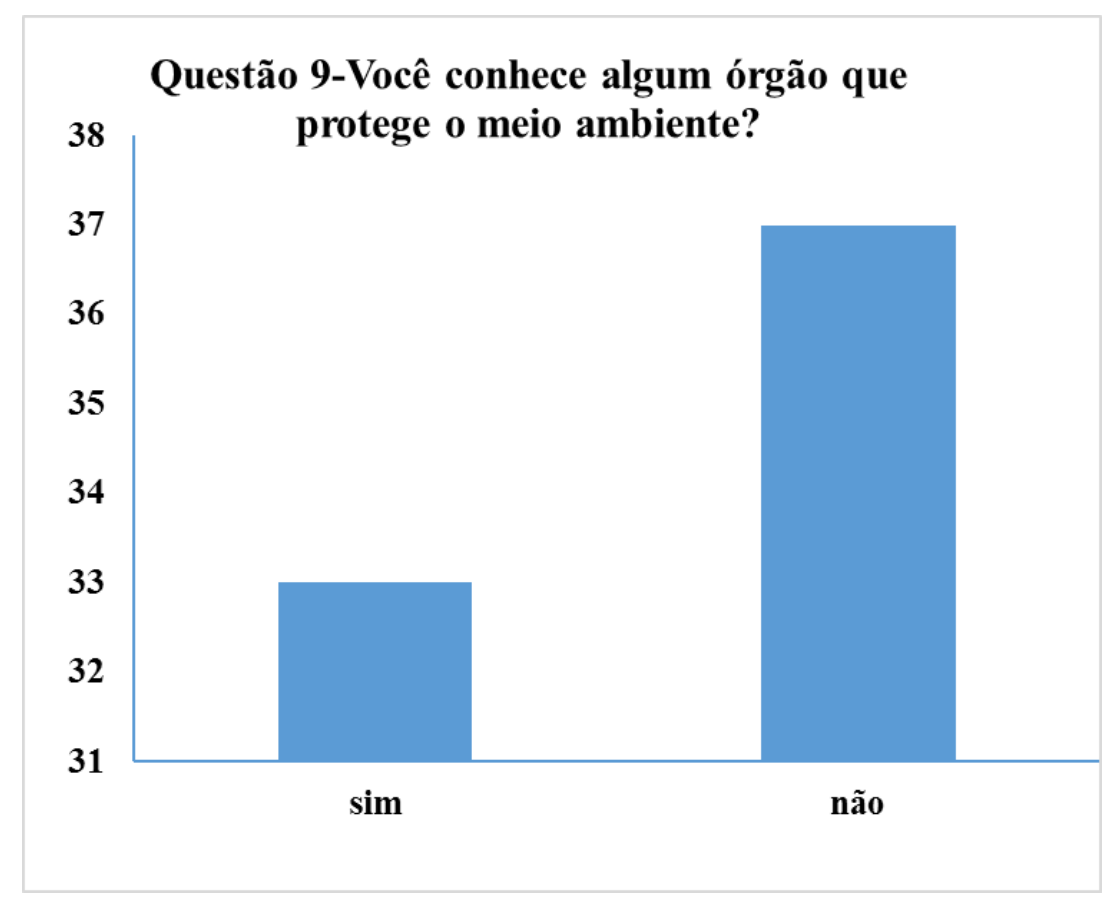

FIGURA 7- Questão 9 (Você conhece algum órgão que protege o meio ambiente?)

Em relação aos níveis de assoreamento dos rios, as respostas foram bastante equilibradas, conforme pode ser observada na FIGURA 8, porém houve prevalência no posicionamento de que houveram alterações relacionadas ao assoreamento do rio, mas com alguns relatos de assoreamento em maiores ou menores proporções, e segundo a pesquisa também nota-se que as respostas variavam conforme a localização das moradias. Portanto, em alguns trechos não foram percebidos níveis de assoreamento, em outros houve pouco, e em outros houveram níveis maiores. 


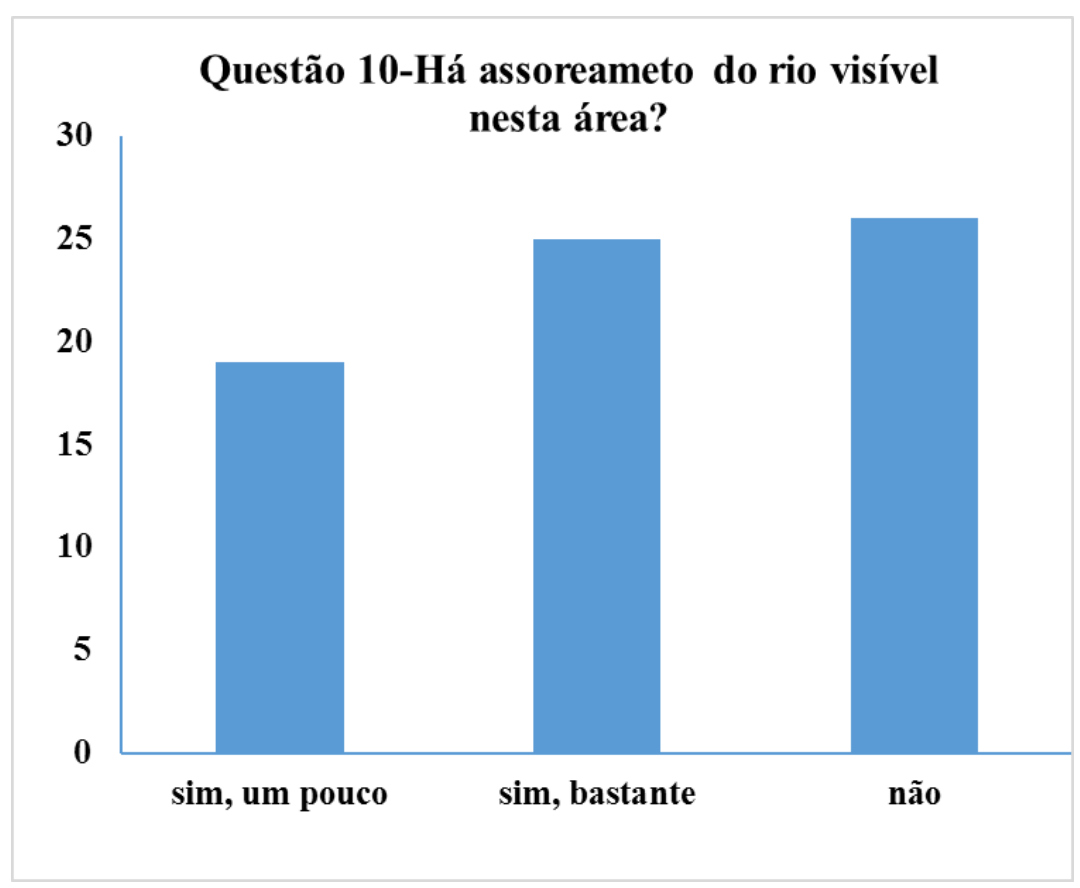

FIGURA 8- Questão 10(Há assoreamento do rio visível nesta área?)

\section{CONCLUSÕES}

Tuan (1980, p. 1) entende a importância da percepção ambiental e que se em algum momento é visada a solução desses problemas, esta percepção precisa ser levada em conta: "[...] percepção, atitudes e valores - preparam-nos primeiramente, a compreender nós mesmos. Sem a auto compreensão não podemos esperar por soluções duradouras para os problemas ambientais que, fundamentalmente, são problemas humanos". Logo, é de extrema relevância levar em consideração o conhecimento da população local, e principalmente que haja introdução a educação ambiental a esses moradores para que haja tomada de consciência e empenho em preservar as matas ciliares. Estudos voltados a este meio, revelam alertas que a própria população pode propiciar e que muitas vezes são despercebidos, como alertas para incentivos e empenho à fiscalização de áreas de proteção, crescimento populacional e falta de planejamento urbano.

\section{REFERENNCIAS}

BRAGA, R. Política Urbana e Gestão Ambiental: considerações sobre o Plano Diretor e zoneamento urbano. In.: CARVALHO, P. F.; BRAGA, R. (Orgs.) Perspectivas de Gestão Ambiental em cidades médias. Rio Claro: LPM - UNESP, 2001, p. 95 a 109.

BURTON, Ian; KATES, Robert W. \& WHITE, Gilbert F. The environmental as hazard. New York: Oxford University, 1978. 240p

DIAS, Genebaldo Freire. Educação Ambiental: princípios e práticas. São Paulo: Gaia, 1992. 224p.

FAGgiOnATO, S. Percepção ambiental. Material de Apoio - Textos, 2009. Disponível em: < http://educar.sc.usp.br/biologia/textos/m_a_txt4.html>. Acessado em: 08 mar 2015 
FELLENBERG, G. Introdução aos Problemas da Poluição Ambiental. Editora EPU, Ed. Da Universidade de São Paulo, 1980.

FERNANDES, R. S., SOUZA, V. J., PELISSARI, V. B., FERNANDES, S.T. Uso da percepção ambiental como instrumento de gestão em aplicações ligadas às áreas educacional, social e ambiental. Rede Brasileira de Centros de Educação Ambiental. Rede CEAS. Noticias, 2009. Disponível em: <http: //www.redeceas.esalq.usp.br/noticias/ Percepcao_Ambiental.pdf > Acessado em: 12 mar. 2015.

GLOAGEN, R. A. B. G.; MELO FILHO, J. F.; SILVA, P. S. O.; DOURADO, C. S.; SILVA JÚNIOR, J. J.; SOUZA, D. L. A. Diagnóstico preliminar de impactos ambientais na micro-bacia do ribeirão do Machado em Cruz das Almas - BA. Revista Brasileira de Agroecologia. v. 2, n. 2, p. 1645-1648, 2007.

GOOGLE, Google Earth. 2017. (Município de Mazagão-AP). Disponível em: <http://www.google.com.br/maps/@0.1160135,51.2878415,15z/data=!3m1!4b1!4m2!6 m1!1s1KxbQ2VZwDlLk_bGqpw3oUHAJHIQ>. Acesso em: 03 fev.2017

MARTINS, S. V.: Recuperação de matas ciliares. $2^{\mathrm{a}}$ Ed. Revista e ampliada. Viçosa: Editora Aprenda Fácil,2007. 255p.

MONTAÑO, M.; SOUZA, M.P. de. A viabilidade ambiental no licenciamento de empreendimentos perigosos no Estado de São Paulo. Engenharia Sanitária e Ambiental, Rio de Janeiro, v. 13, n. 4,p. 435-42. 2008.

TAGLIACARNE, G. Pesquisa de Mercado: técnica e prática. São Paulo: Atlas, 1978, pg. 173.

TUAN, Y. F. Topofilia: um estudo da percepção, atitudes e valores do meio ambiente. Tradução de Lívia de Oliveira. São Paulo; Rio de Janeiro: Difel, 1980.

VIEIRA, Raphael Ricardo Menezes Alves. A utilidade das matas ciliares como área de preservação permanente. Jus Navigandi, Teresina, ano 18, n. 3725, [12] set. [2013]. Disponível em: <http://jus.com.br/artigos/25273>. 